\title{
The Effects of Different Techniques and Energy Used in Nd: Yag Laser Posterior Capsulotomy on Intraocular Pressure: A Prospective Study
}

\author{
Bhatnagar A, Saxena AK and Fahim S* \\ Anterior Segment Department, Dr Mohanlal Memorial \\ Gandhi Eye Hospital Aligarh, India \\ *Corresponding author: Fahim S, Anterior Segment \\ Department, Dr Mohanlal Memorial Gandhi Eye Hospital \\ Aligarh, Near Shakir Sirs Coaching Classes, Abdullah \\ Girls College Road, India
}

Received: March 27, 2017; Accepted: April 18, 2017; Published: April 25, 2017

\begin{abstract}
Purpose: To study the relationship between energy used and its effect on IOP in different capsulotomy techniques i.e. cruciate, circular and inverted ' $u$ '.

Subjects and Methods: The study was conducted in 154 patients from the out patients department who fulfilled the inclusion criteria and developed posterior capsular opacification following successful cataract surgery. And the patients were randomly divided into three groups. Group I undergoing cruciate technique, group II undergoing circular technique and group III undergoing inverted $U$ technique. Preprocedure intraocular pressure was recorded by using applanation tonometry. Patients undergoing Nd: Yag laser capsulotomy were seen after 2 hours, 1 day, 1week, 1 month and 3 months and IOP was recorded. The outcome was measured in terms of number of shots given in the technique, total energy used and intra ocular pressure changes after the laser.
\end{abstract}

Results: In the light of our present study, we have found that group II which is circular technique group consumes higher no. of laser shots and higher amount of total laser energy which leads to transient rise in intraocular pressure. Correlation was found between the IOP readings obtained and amount of total laser energy used.

Conclusions: The techniques cruciate and inverted $\mathrm{U}$ appears to be better and safer than the circular technique in terms of amount of energy used and the complications associated with it.

Keywords: Posterior capsular opacification; Intraocular pressure; Nd: Yag laser capsulotomy

\section{Abbreviations}

PCO: Posterior Capsular Opacification; IOP: Intraocular Pressure; IOL: Intraocular Lens

\section{Introduction}

Posterior capsular opacification (PCO) also called as "after" or secondary cataract is the opacity which follows extra capsular extraction of lens. It is formed due to the migration of equatorial capsular epithelial cells towards the posterior capsule. PCO occurs as result of formation of opaque secondary membrane by lens epithelial cell proliferation, transformation of lens epithelial cells into fibroblasts with contractile element and collagen deposition [1]. PCO is the most common delayed complication of cataract surgery that causes decreased vision, glare and other symptoms similar to that of original cataract; PCO causes reduction in visual acuity and contrast sensitivity by obstructing the view or by scattering the light that is perceived as glare by the patient. It also decreases the field of view during therapeutic and diagnostic procedures and also causes uniocular diplopia [2].

Posterior capsular opacification is usually found in three forms, thin membranous, the ring of Sommerring, Elschnig pearls forming dense membrane /fibrous membrane.
The commonly found type is membranous or capsular wrinkling; it is formed by myofibroblastic differentiation of the migrating epithelial cells, which acquire contractile properties. The stimulus for proliferation, migration and metaplasia of lens epithelial cells is not entirely understood.

The other major form of PCO is formation of Elschnig pearls and bladder cells, which also occurs months to years after surgery. The term Hirschberg-Elsching pearls was coined by Elschnig in 1911. It connotes a process caused by rupture of anterior lens capsule following surgical trauma, disrupted lens epithelial cells come out through the tear into the aqueous and settle on iris and other anterior segment structures. Clinically on slit lamp examination these cluster of cells resemble pearls.

Cataract surgeons have shortened the term "Hirschberg-Elschnig pearls" to pearls when referring to PCO that occurs when the cells migrate into the visual axis following ECCE/Phaco emulsification. When cells are small they are called pearls and when they are large and round they are known as bladder cells.

Fibrous type of PCO connotes a gray white band or plaque like opacity that may be recognized in the early post-operative period or later. The opacity developed months to years after the surgery is caused by migration of anterior lens epithelium from the cut edge 
of the anterior lens capsule on to the posterior capsule. These cells undergo fibrous metaplasia and produces collagen which causes a dense fibrous plaque.

The rate of PCO formation depend on the type of surgery done (ECCE/Phaco emulsification), age of patient, surgeon, type of lens implanted and duration after surgery. It is more common in young patients and patients of uveitis and traumatic cataracts. The incidence of PCO was reported to be $20.7 \%$ at two years and $28.5 \%$ at five years after cataract PCO [3].

Neodymium doped yttrium- aluminium -garnet (Nd: Yag) laser is a solid state laser with a wavelength of 1064 nanometer [4]. The laser works on the principle of photo disruption [5]. When laser is focused and delivered in a short period of time it causes ionization of atoms at the focal point as a result of high electromagnetic field. This ionized state of tissue is known as plasma [6]. Here the temperature reaches upto $15000 \mathrm{c}$.

It causes acoustic and mechanical shock waves which disrupts tissues. This is the basis of its microsurgical capability.

Yttrium aluminum garnet (yag) capsulotomies were developed in early 1980's by Dr Aron Rosa and Frankhauser. Nd: Yag laser capsulotomy has been gradually replacing surgical capsulotomy as it is safe, noninvasive, effective, day care procedure and considered as standard treatment [7].

There are certain complications associated with the Nd: Yag laser capsulotomy like - transient intra ocular pressure elevation, cystoid macular odema, corneal odema, pitting of intraocular lens, IOL damage, decentration and dislocation into the vitreous, iritis, anterior vitreous phase destruction and opacification, retinal tears and detachments, lowering of endothelial cell count and macular hemorrhage [8]. Among these rise in IOP is the most common side effect of Nd: Yag laser capsulotomy [9].

Several Nd: Yag laser techniques have been described for posterior capsulotomy in patients of PCO. The two posterior capsulotomy techniques most commonly used nowadays are cruciate technique and circular techniques $[8,10]$. In cruciate method the first pulsed laser shot is given off the visual axis and following shots are given horizontally in visual axis and then this is expanded in vertical axis [8]. While in circular method the first pulsed shot is given in the visual axis and then extended along the tension lines in circular fashion till appropriate size opening is created. An inverted ' $u$ ' method was introduced to make up for the weaknesses that two methods possessed $[10,11]$. In inverted $U$ method the laser shots are given $1.5 \mathrm{~mm}$ away from the visual axis above and on both sides but only $1 \mathrm{~mm}$ below the visual axis.

Usually pulsed Q-switched Nd: Yag laser is used in capsulotomy, it is safer and complications are minimal with it $[12,13]$. The total pulsed energy required for a laser capsulotomy differs significantly between PCO types [14]. The total amount of energy used give rise to different complications. Various reasons for rise in intra ocular pressure after Nd: Yag laser capsulotomy like deposition of debris in trabecular meshwork, pupillary block and inflammatory swelling of ciliary body or iris root. Energy used can vary in different techniques and type of PCO.
The purpose of this prospective randomized comparative trial is to study the different capsulotomy techniques and their relation with energy and intra ocular pressure.

\section{Materials and Methods}

It was a Prospective Randomized Comparative Study. This study was conducted in outpatients department of Dr. Mohan Lal Memorial Gandhi Eye Hospital Aligarh. Permission for this study was obtained from the ethical committee of the hospital. The study was conducted in 154 patients from the out patients department who fulfilled the inclusion criteria and developed posterior capsular opacification following successful cataract surgery.

\section{Inclusion criteria}

1. Age of patients between $40-70$ years.

2. Patients having uneventful cataract surgery with posterior chamber IOL implant.

3. Patients having best corrected vision of $6 / 60$ or below from Snellen chart.

\section{Exclusion criteria}

1. Patients having any anterior segment pathology like conjunctivitis, keratitis, symblepharon, corneal degeneration, corneal dystrophy, anterior uveitis.

2. Patients having glaucoma, vitritis, macular oedema, diagnosed diabetic retinopathy and any other retinal disease.

3. Patients operated for traumatic cataract.

4. Patients with dislocated IOL or decentered IOL.

5. Patients with combined procedure trabeculectomy with cataract surgery.

6. Patients less than 40 years of age and above 70 years with IOL.

7. Patients having PCO of less than 3 months.

\section{Methodology}

A detailed history was taken and through ophthalmic examination was done.

Patients were examined according to the study performa. Informed consent was taken from the patients in their own language in a prescribed bilingual format. The type of PCO was categorized into three types i.e membranous, fibromembranous and fibrous on the basis of slit lamp examination done after dilatation. And the patients were randomly divided into three groups. Group I undergoing cruciate technique, group II undergoing circular technique and group III undergoing inverted U technique. Preprocedure intraocular pressure was recorded by using applanation tonometry.

Intraocular pressure: It was taken by using Goldmann's applanation tonometer mounted on the slit lamp. Two drops of xylocaine eye drops (4\%) at an interval of five minutes were used to anesthetise the cornea of both the eyes. A sterile fluorsciene paper strip was used to make the tear film fluoroscent applied in the lower fornix. Cobalt Blue filter was placed in front of the fully open slit lamp beam which was directed towards the prism and was fixed at an angle of 60 degrees under the low magnification (10X). With the patient 
Table 1: Group wise distribution of cases $(n=154)$.

\begin{tabular}{|c|c|c|c|c|}
\hline SN & Group & $\begin{array}{c}\text { Technique used for } \\
\text { capsulotomy }\end{array}$ & No. of patients & Percentage \\
\hline 1. & I & Cruciate & 51 & 33.1 \\
\hline 2. & II & Circular & 51 & 33.1 \\
\hline 3. & III & Inverted U & 52 & 33.8 \\
\hline
\end{tabular}

looking straight ahead the prism was bought into contact with the cornea and at this point the limbus was illuminated. The spring knob was preset at 1.0. Two blue half rings were seen through the eye piece of the slit lamp, these half rings were adjusted and the sping knob is rotated to bring the inner borders of these rings in contact, at this point the readings of the knob is recorded. This reading was then multiplied by 10 and the final pressure reading is noted.

Nd: Yag laser posterior capsulotomy procedure: Laser posterior capsulotomy was performed in the outpatient department as a day care procedure. Appa Nd: Yag Laser model no.307 was used, it is a Q switched burst mode laser. Before beginning the procedure informed consent was taken by the patients. We did not use any pressure lowering drugs before the procedure. Weak dilating drops were used for better visualization of the posterior capsule. The patient was then asked to put the head on the chinrest of a slit lamp microscope, to which laser was attached. The patient was instructed to remain still as we focused the posterior capsule. A headstrap was used to keep the head stable. Four mires were seen through the slitlamp, of which two anterior mires were on the cornea and two posterior on the intraocular lens. While focusing on the posterior capsule, two posterior mires were fused and laser shots were given to disrupt the posterior capsule. This disruption of the posterior capsule was done by three different techniques i.e circular, cruciate and inverted " $U$ ".

In circular method the first shot was given at the visual axis and subsequent shots were given in circular fashion on the tension lines to create an appropriate opening $(3 \mathrm{~mm})$ in the posterior capsule.

In case of cruciate method first shot was given at the visual axis and subsequent shots were extended horizontally, after horizontal slit formation the shots were given vertically till a cross shaped opening was created.

While in third method the first shot was given $1 \mathrm{~mm}$ below and laterally to the visual axis and subsequent shots were given in an inverted " $U$ " fashion till a free posterior capsular flap was created which settled down by gravitation force.

According to these three techniques the patients were divided into three groups and posterior capsulotomies were performed. The outcome was measured in terms of number of shots given in the technique, total energy used and intra ocular pressure changes after the laser.

\section{Follow up}

Patients undergoing Nd: Yag laser capsulotomy were seen after 2hours, 1 day, 1 week, 1 month and 3 months and IOP was recorded. If the IOP was raised to $8 \mathrm{mmHg}$ above the baseline then antiglaucoma treatment was started with topical beta-blocker $(0.5 \%$ timolol maleate) twice a day and oral acetazolamide $250 \mathrm{mg}$ thrice a day for three days. Rests of patients were given a combination of antibiotic and anti-inflammatory topical drops for four times a day.

\section{Statistical analysis}

The statistical analysis was done using SPSS (Statistical Package for Social Sciences) Version 15.0 statistical Analysis Software. Chisquare test was used for comparison of categorical data, Analysis of variance followed by Independent samples "t" test was used to compare the continuous data.

Analysis of Variance: Analysis of Variance (ANOVA): The ANOVA test was used to compare the within group and between group variances amongst the study groups. Analysis of variance of different study groups at a particular time interval revealed the differences amongst them. ANOVA provided " $F$ " ratio, where a higher " $F$ " value depicted a higher inter-group difference.

\section{$F=$ Mean of Sum of Between Group Differences/ Mean of Sum of within Group Differences}

The data has been represented as frequencies and percentages and mean and standard deviation. A "p" value less than 0.05 indicated a statistically significant association.

\section{Results}

In our study we have taken 154 patients and divided them into three groups i.e Group I cruciate, Group II circular and Group III inverted U. In our study the age of the patients ranged from $40-70 \mathrm{yrs}$, the mean age was $61.72 \pm 8.11 \mathrm{yrs}$. Out of total patients $79(51.3 \%)$ were males and $75(48.7 \%)$ were females; overall right eye was more commonly involved (53.9\%) than left eye (46.1\%). The pre procedure BCVA ranged from $1 / 60$ to $6 / 60$, most of the patients $(>90 \%)$ had pre procedure BCVA of $6 / 60$. There were patients having $51(33.1 \%)$ of membranous type of PCO, 51(33.1\%) have fibromembranous type; while fibrous type was present in $52(33.8 \%)$. The pre procedure intraocular pressure ranged from $10-18 \mathrm{~mm}$ of $\mathrm{Hg}$, mean IOP was $14.06 \pm 2.13$. Statistically there was no significant difference in IOP among the three groups (Table 1).

The pulse energy ranged from 1.5 to $5.0 \mathrm{mj}$ per shot; in Group I, II and III the pulse energy was $2.54 \pm 0.79,2.66 \pm 0.98,2.39 \pm 0.74 \mathrm{mj}$ respectively. The overall mean pulse energy used was $2.53 \pm 0.85 \mathrm{mj}$. On comparison between the groups there was no statistical significance found $(\mathrm{p}=0.290)$. No. of shots used ranged from 5 to 27 , in Group I, II and III the no of shots given were $8.80 \pm 3.04 ; 16.12 \pm 6.60 ; 9.31 \pm 4.09$

\begin{tabular}{|c|c|c|c|c|c|c|}
\hline SN & Characteristic & Total $(n=154)$ & Group I $(n=51)$ & Group II $(n=51)$ & Group III $(n=52)$ & Statistical significance \\
\hline 1. & Mean Age \pm SD (Range) in years & $\begin{array}{c}61.72 \pm 8.11 \\
(40-85)\end{array}$ & $\begin{array}{c}61.18 \pm 7.77 \\
(45-70)\end{array}$ & $\begin{array}{c}63.63 \pm 8.21 \\
(40-85)\end{array}$ & $\begin{array}{c}60.38 \pm 8.12 \\
(40-70)\end{array}$ & $F=2.270 ; p=0.107(N S)$ \\
\hline \multirow{3}{*}{2.} & Sex & & & & & \\
\hline & Male & $79(51.3 \%)$ & $26(51.0 \%)$ & $24(47.1 \%)$ & $29(55.8 \%)$ & \multirow{2}{*}{$x^{2}=0.785 ; p=0.675$ (NS) } \\
\hline & Female & $75(48.7 \%)$ & $25(49.0 \%)$ & $27(52.9 \%)$ & $23(44.2 \%)$ & \\
\hline
\end{tabular}


Table 3: Intergroup comparison of Pulse energy, No. of shots and Total energy.

\begin{tabular}{|c|c|c|c|c|c|c|c|c|c|c|c|}
\hline \multirow{2}{*}{ SN } & \multirow{2}{*}{ Characteristic } & \multicolumn{2}{|c|}{ Total $(n=154)$} & \multicolumn{2}{|c|}{ Group I (n=51) } & \multicolumn{2}{|c|}{ Group II $(n=51)$} & \multicolumn{2}{|c|}{ Group III (n=52) } & \multicolumn{2}{|c|}{ Statistical significance } \\
\hline & & Mean & $\pm \mathrm{SD}$ & Mean & $\pm S D$ & Mean & $\pm \mathrm{SD}$ & Mean & $\pm \mathrm{SD}$ & $\mathbf{F}$ & ‘p’ \\
\hline 1. & Pulse energy (mj) & 2.53 & 0.85 & 2.54 & 0.79 & 2.66 & 0.98 & 2.39 & 0.74 & 1.249 & 0.290 \\
\hline 2. & No. of shots & 11.40 & 5.83 & 8.80 & 3.04 & 16.12 & 6.60 & 9.31 & 4.09 & 36.87 & $<0.001$ \\
\hline 3. & Total energy (mj) & 30.32 & 20.14 & 22.68 & 9.97 & 45.54 & 25.18 & 22.90 & 12.32 & 30.02 & $<0.001$ \\
\hline \multicolumn{12}{|c|}{ Between Group comparison (Tukey HSD test) } \\
\hline \multirow{2}{*}{ SN } & \multirow{2}{*}{ Characteristic } & \multicolumn{3}{|c|}{ | vs || } & \multicolumn{3}{|c|}{ I vs III } & \multicolumn{4}{|c|}{ II vs III } \\
\hline & & MD & SE & 'p’' & MD & SE & 'p’ & MD & SE & \multicolumn{2}{|c|}{ ‘p’ } \\
\hline 1. & Pulse energy (mJ) & -0.12 & 0.17 & 0.762 & 0.14 & 0.17 & 0.660 & 0.26 & 0.17 & \multicolumn{2}{|c|}{0.259} \\
\hline 2. & No. of shots & -7.31 & 0.95 & $<0.001$ & -0.50 & 0.95 & 0.856 & 6.81 & 0.95 & \multicolumn{2}{|c|}{$<0.001$} \\
\hline 3. & Total energy (mJ) & -22.86 & 3.40 & $<0.001$ & -0.23 & 3.38 & 0.998 & 22.64 & 3.38 & \multicolumn{2}{|c|}{$<0.001$} \\
\hline
\end{tabular}

Table 4: Intergroup comparison of 2-hr Post-Procedure IOP.

\begin{tabular}{|c|c|c|c|c|c|c|c|c|}
\hline SN & \multicolumn{2}{|c|}{ Group } & No. of cases & Mean & SD & \multicolumn{2}{|c|}{ Minimum } & Max \\
\hline 1. & \multicolumn{2}{|l|}{1} & 51 & 17.69 & 2.24 & \multicolumn{2}{|c|}{12} & 22 \\
\hline 2. & \multicolumn{2}{|l|}{ II } & 51 & 20.63 & 4.15 & \multicolumn{2}{|c|}{12} & 30 \\
\hline 3. & \multicolumn{2}{|l|}{ III } & 52 & 17.69 & 2.58 & \multicolumn{2}{|c|}{12} & 22 \\
\hline & \multicolumn{2}{|c|}{ Total } & 154 & 18.66 & 3.38 & \multicolumn{2}{|c|}{12} & 30 \\
\hline \multicolumn{9}{|c|}{ Between Group comparison (Tukey HSD test) } \\
\hline \multicolumn{3}{|c|}{ I vs II } & \multicolumn{3}{|c|}{ I vs III } & \multicolumn{3}{|c|}{ II vs III } \\
\hline MD & SE & ‘p’ & MD & SE & 'p' & MD & SE & 'p' \\
\hline-2.94 & 0.61 & $<0.001$ & -0.01 & 0.61 & 1.000 & 2.94 & 0.61 & $<0.001$ \\
\hline
\end{tabular}

$F=15.333 ; p<0.001$.

respectively. The mean no. of shots was $11.40 \pm 5.83$. On comparing the Group I and Group III with that to Group II there was significant inter group difference $(\mathrm{p}<0.001)$. While on comparing Group I and Group III there was no statistically significant difference found $(\mathrm{p}=0.856)$ (Table 2$)$.

The total energy used ranged from 8 to $81 \mathrm{mj}$. In Group I, II and III the total energy used was $22.68 \pm 9.97 ; 45.54 \pm 25.18 ; 22.90 \pm 12.32 \mathrm{mj}$ respectively. Over all mean total energy used was $30.32 \pm 20.14 \mathrm{mj}$. On in between comparison, there was a significant difference of no. of shots and total energy $(\mathrm{p}<0.05)$ in Group II as compared to Group I and Group III (Table 3).

2-hr post-procedure, IOP values ranged from 12 to $30 \mathrm{mmHg}$ in different groups. Mean IOP was $17.69 \pm 2.24,20.63 \pm 4.15$ and $17.69 \pm 2.58 \mathrm{mmHg}$ in Groups I, II and III. Statistically, intergroup difference in IOP was significant $(\mathrm{p}<0.001)$. On between group comparison, Group II was found to be having significantly higher mean IOP as compared to the other two groups ( $<<0.001)$, however, no significant difference was observed between Groups I and III (Table 4).

1-day post-procedure, IOP values ranged from 12 to $18 \mathrm{mmHg}$ in different groups. Mean IOP was $14.00 \pm 1.88,15.24 \pm 2.06$ and $13.85 \pm 1.72 \mathrm{mmHg}$ in Groups I, II and III. Statistically, intergroup difference in IOP was significant $(\mathrm{p}<0.001)$. On between group comparison, Group II was found to be having significantly higher mean IOP as compared to the other two groups ( $<<0.001)$, however, no significant difference was observed between Groups I and III (Table 5).
Table 5: Intergroup comparison of 1-day Post-Procedure IOP.

\begin{tabular}{|c|c|c|c|c|c|c|c|c|}
\hline SN & Group & \multicolumn{2}{|c|}{ No. of cases } & Mean & \multicolumn{2}{|c|}{ SD } & Minimum & Max \\
\hline 1. & I & \multicolumn{2}{|c|}{51} & 14.00 & \multicolumn{2}{|c|}{1.88} & 12 & 18 \\
\hline 2. & II & \multicolumn{2}{|c|}{51} & 15.24 & \multicolumn{2}{|c|}{2.06} & 12 & 18 \\
\hline 3. & III & \multicolumn{2}{|c|}{52} & 13.85 & \multicolumn{2}{|c|}{1.72} & 12 & 18 \\
\hline & Total & \multicolumn{2}{|c|}{154} & 14.36 & \multicolumn{2}{|c|}{1.98} & 12 & 18 \\
\hline \multicolumn{9}{|c|}{ Between Group comparison (Tukey HSD test) } \\
\hline \multicolumn{3}{|c|}{ I vs II } & \multicolumn{3}{|c|}{ I vs III } & \multicolumn{3}{|c|}{ II vs III } \\
\hline MD & SE & 'p' & MD & SE & 'p' & MD & SE & 'p' \\
\hline-1.24 & 0.37 & 0.003 & 0.15 & 0.37 & 0.910 & 1.40 & 0.37 & 0.001 \\
\hline
\end{tabular}

$F=8.395 ; p<0.001$.

At one week, one month and three month there was no statistically significant change in intraocular pressure observed.

On overall combined evaluation as well as evaluating different groups independently, mean change in IOP at $2 \mathrm{hr}$ and 1 day interval was seen to be higher in those subgroups where energy used was of higher order and lower in those subgroups where energy used was of lower order. The association was significant statistically too at $2 \mathrm{hr}$ and 1 day interval for overall evaluation $(\mathrm{p}<0.05)$ and at $2 \mathrm{hr}$ interval in all the groups independently $(\mathrm{p}<0.05)$. At subsequent intervals (day 7 onwards), the change from baseline IOP was of minor order and was mainly governed randomly irrespective of amount of energy used for capsulotomy (Table 6).

\section{Discussion}

Posterior capsular opacification is one of the major post operative delayed complication of cataract surgery. The overall incidence of PCO is $11.8 \%$ at one year; $20.7 \%$ at two year and $28.4 \%$ at five year after cataract surgery. Worldwide Nd: Yag laser capsulotomy has become the standard treatment for the posterior capsular opacification. Ophthalmologist has used it successfully for last 20yrs with excellent visual recovery; however the procedure is not entirely risk free.

PCO causes reduction in visual acuity and contrast sensitivity by obstructing the view or by scattering the light that is perceived as glare by the patient. It also decreases the field of view during therapeutic and diagnostic procedures and also causes uniocular diplopia.

In Nd: Yag laser the extremely small area of the posterior capsule is disrupted by applying certain amount of energy; at the area of 
Table 6: Association between Energy Used and IOP Changes as compared to baseline. Values depict mean change in IOP $\pm S D$.

\begin{tabular}{|c|c|c|c|c|c|c|c|c|c|c|c|c|c|}
\hline \multirow[b]{2}{*}{ SN } & \multirow[b]{2}{*}{ Time interval } & \multicolumn{10}{|c|}{ Energy levels } & \multirow[b]{2}{*}{ 'F' } & \multirow[b]{2}{*}{ 'p' } \\
\hline & & \multicolumn{2}{|c|}{$\begin{array}{c}\leq 10 \mathrm{~mJ} \\
(\mathrm{n}=22)\end{array}$} & \multicolumn{2}{|c|}{$\begin{array}{c}11-20 \mathrm{~mJ} \\
(\mathrm{n}=39)\end{array}$} & \multicolumn{2}{|c|}{$\begin{array}{c}21-30 \mathrm{~mJ} \\
(n=31)\end{array}$} & \multicolumn{2}{|c|}{$\begin{array}{c}31-40 \mathrm{~mJ} \\
(n=26)\end{array}$} & \multicolumn{2}{|c|}{$\begin{array}{c}>40 \mathrm{~mJ} \\
(\mathrm{n}=36)\end{array}$} & & \\
\hline \multicolumn{14}{|c|}{ Overall (n=154) } \\
\hline & & Mean & SD & Mean & SD & Mean & SD & Mean & SD & Mean & SD & & \\
\hline 1. & $2 \mathrm{hr}$ & 1.91 & 1.57 & 3.13 & 1.82 & 4.19 & 1.49 & 4.77 & 1.80 & 8.06 & 2.97 & 39.955 & $<0.001$ \\
\hline 2. & 1 day & 0.09 & 1.31 & 0.65 & 1.68 & -0.06 & 0.36 & -0.15 & 0.54 & 0.67 & 1.51 & 3.176 & 0.015 \\
\hline 3. & 7 days & -0.09 & 1.31 & -0.14 & 1.36 & -0.06 & 0.36 & -0.16 & 0.55 & 0.11 & 0.82 & 0.412 & 0.800 \\
\hline 4. & 1 month & -0.18 & 1.22 & -0.24 & 1.26 & -0.06 & 0.36 & -0.17 & 0.58 & 0.00 & 0.83 & 0.381 & 0.822 \\
\hline 5. & 3 months & -0.18 & 1.22 & -0.34 & 1.24 & -0.06 & 0.36 & -0.09 & 0.43 & 0.00 & 0.84 & 0.763 & 0.551 \\
\hline \multicolumn{14}{|c|}{ Group I $(n=51)$} \\
\hline \multicolumn{2}{|r|}{$\mathrm{N}$} & \multicolumn{2}{|c|}{9} & \multicolumn{2}{|c|}{11} & \multicolumn{2}{|c|}{18} & \multicolumn{2}{|c|}{13} & \multicolumn{2}{|c|}{0} & & \\
\hline 2. & 1 day & -0.44 & 1.67 & -0.18 & 1.66 & -0.11 & 0.47 & 0.00 & 0.00 & & & 0.324 & 0.808 \\
\hline 3. & 7 days & -0.44 & 1.67 & -0.18 & 1.40 & -0.11 & 0.47 & 0.00 & 0.00 & & & 0.364 & 0.779 \\
\hline 4. & 1 month & -0.44 & 1.67 & -0.18 & 1.40 & -0.11 & 0.47 & 0.00 & 0.00 & & & 0.348 & 0.791 \\
\hline 5. & 3 months & -0.44 & 1.67 & -0.36 & 1.21 & -0.11 & 0.47 & 0.00 & 0.00 & & & 0.523 & 0.669 \\
\hline \multicolumn{14}{|c|}{ Group II $(n=51)$} \\
\hline \multicolumn{2}{|r|}{$\mathrm{N}$} & \multicolumn{2}{|c|}{2} & \multicolumn{2}{|c|}{15} & \multicolumn{2}{|c|}{0} & \multicolumn{2}{|c|}{2} & \multicolumn{2}{|c|}{32} & & \\
\hline 1. & $2 \mathrm{hr}$ & 4.00 & 0.00 & 2.93 & 1.67 & & & 5.00 & 1.41 & 8.19 & 3.02 & 14.41 & $<0.001$ \\
\hline 2. & 1 day & 1.00 & 1.41 & 1.69 & 1.88 & & & -1.00 & 1.41 & 0.75 & 1.59 & 2.029 & 0.123 \\
\hline 3. & 7 days & 0.00 & 2.83 & -0.23 & 1.89 & & & -1.00 & 1.41 & 0.13 & 0.87 & 0.607 & 0.614 \\
\hline 4. & 1 month & -1.00 & 1.41 & -0.49 & 1.67 & & & -1.00 & 1.41 & 0.00 & 0.88 & 1.191 & 0.323 \\
\hline 5. & 3 months & -1.00 & 1.41 & -0.63 & 1.71 & & & -1.00 & 1.41 & 0.00 & 0.89 & 1.403 & 0.254 \\
\hline 1. & $2 \mathrm{hr}$ & 1.64 & 0.81 & 2.92 & 1.93 & 4.62 & 1.71 & 5.45 & 1.29 & 7.00 & 2.58 & 13.384 & $<0.001$ \\
\hline 2. & 1 day & 0.36 & 0.81 & 0.15 & 0.55 & 0.00 & 0.00 & -0.18 & 0.60 & 0.00 & 0.00 & 1.540 & 0.206 \\
\hline 3. & 7 days & 0.18 & 0.60 & 0.00 & 0.00 & 0.00 & 0.00 & -0.18 & 0.60 & 0.00 & 0.00 & 1.175 & 0.334 \\
\hline 4. & 1 month & 0.18 & 0.60 & 0.00 & 0.00 & 0.00 & 0.00 & -0.20 & 0.63 & 0.00 & 0.00 & 1.214 & 0.318 \\
\hline 5. & 3 months & 0.18 & 0.60 & 0.00 & 0.00 & 0.00 & 0.00 & 0.00 & 0.00 & 0.00 & 0.00 & 0.878 & 0.485 \\
\hline
\end{tabular}

contact of laser there is formation of electromagnetic field which strips electrons from the atoms and results in formation of plasma along with formation of shockwave which is responsible for the photo disruption of the posterior capsule. At the site the temperature rise is in thousands of degrees.

In the above process there is tissue disruption by plasma formation as well as by shockwave which is responsible for different complications after laser like rise in intraocular pressure, uveitis, retinal detachment, IOL pitting etc. Among these rise in intraocular pressure is most frequently seen.

There are different techniques by which Nd: Yag laser posterior capsulotomy can be done but every technique has its drawbacks. The different techniques used nowadays are cruciate, circular, and inverted $U$.

As there is little data available on the use of the different capsulotomy technique, in the present study we compared these three techniques of Nd: Yag laser posterior capsulotomy.
In our study we have found that the higher amount of energy was used to perform circular technique which goes in accordance with the study done by Necip Kara et al. Similarly there was less amount of energy gone in inverted $U$ technique which is similar to the study done by Zeki et al.

In a study done by Rahul Bhargava et al [15] on 474 patients they found that larger amount of energy used gave rise to intraocular pressure spike and increase rate of complications like IOL pitting etc. Similarly in a study done by Bilal Khan et al [16] they showed $12.8 \%$ IOL pitting along with transient rise in IOP. In our study large amount of energy was delivered in group II and hence rise in IOP was also found in the same group as compared with the other two groups.

In a study done by Bhargava $\mathrm{R}$ et al [17] they randomly selected the patients and performed capsulotomy and found that there was increase in intraocular pressure following laser at $1.5-4 \mathrm{hrs}$. In our study we have significant rise in intraocular pressure at $2 \mathrm{hrs}$ and 1 day in all the three groups and on intergroup comparison also there was 
significant rise $(\mathrm{p}<0.001)$.

In a study done by Claudia U. Richter et al [18] they found that those patients who had undergone more than $200 \mathrm{mj}$ of laser energy showed very quick rise in intraocular pressure. In other similar studies done by Jayne Ge et al [19] and Larrañaga-Osuna G et al [20] both showed rise in IOP at one hour along with persistent elevation in some percentage of patients. Our study goes in accordance with these as there was acute rise in IOP at two hours and a definite correlation with energy was also found.

Similarly in a study done by Stuart Fourman et al [21], they showed transient rise in IOP just after laser along with long term elevation in IOP. In our study there was elevation in IOP at two hours in all the three groups as well as on inter group comparison the change was statistically significant.

In a study done by Waseem $\mathrm{M}$ et al [22] they performed Nd: Yag laser capsulotomy in two groups one with low energy and high energy and found out that there was significant rise in intraocular pressure in high energy group. In our study Group II has shown higher amount of energy as well as significant rise in intraocular pressure $(\mathrm{p}<0.001)$.

In a study done by Arlo C Terry et al [23] showed transient rise in IOP at three hours but they concluded that there was no correlation between the amount of energy used and the spike in intraocular pressure. A study done by Schubert HD [24] also showed similar results. In our study there was transient rise in IOP at two hours and we have found statistically significant correlation of rise in IOP with the energy used in circular technique.

Walter J Stark et al [25] analysed 2110 cases that had undergone Nd: Yag laser capsulotomy and concluded that there was rise in intraocular pressure at $1.5-4 \mathrm{hrs}$ after laser. In our study we have found a statistically significant rise in intraocular pressure at $2 \mathrm{hrs}$ and 1 day in all the three groups as well as among the three groups.

In the light of our present study, we have found that group II which is circular technique group consumes higher no. of laser shots and higher amount of total laser energy which leads to transient rise in intraocular pressure. While in the other two Groups I, III (cruciate, inverted $U$ respectively) there was no significant rise in intraocular pressure seen on intergroup comparison; the no of shots of laser and total amount of energy was also less used as compared to group II. So the two techniques -cruciate and inverted $U$ found out to be superior to the third technique ie circular in terms of laser energy consumption, intraocular pressure rise and other complications.

\section{References}

1. McDonnell PJ, Zarbin MA, Green WR. Posterior Capsule Opacification in Pseudophakic Eyes. Ophthalmology. 1983; 90: 1548-1553.

2. Khanzada MA, Jatoi SM, Narsani AK, Dabir SA, Gul S. Is the Nd: YAG Laser a Safe Procedure for Posterior Capsulotomy? Pak J Ophthalmol. 2008; 24.

3. Karahan E, Er D, Kaynak S. An Overview of Nd: YAG Laser Capsulotomy. Med Hypothesis Discov Innov Ophthalmol. 2014; 3: 45-50.

4. Aslam TM, Devlin H, Dhillon B. Use of Nd: YAG laser capsulotomy. Survey of ophthalmology. 2003; 48: 594-612.

5. Gore VS. The study of complications of Nd: YAG laser capsulotomy. International Journal of Bioinformatics Research. 2012; 4: 265.
6. Geerling G, Roider J, Schmidt-Erfurt U, Nahen K, El-Hifnawi ES, Laqua H, et al. Initial clinical experience with the picosecond Nd: YLF laser for intraocular therapeutic applications. British journal of ophthalmology. 1998; 82: 504-509.

7. Durham DG, Gills JP. Three thousand YAG lasers in posterior capsulotomies: an analysis of complications and comparison to polishing and surgical discissions. Trans Am Ophthalmol Soc. 1985; 83: 218-235.

8. Kara N, Evcimen Y, Kirik F, Agachan A, Yigit FU. Comparison of two laser capsulotomy techniques: cruciate versus circular. In Seminars in ophthalmology. 2014; 29: 151-155.

9. Jahn CE, Emke M. Long-term elevation of intraocular pressure after neodymium: YAG laser posterior capsulotomy. Ophthalmologica. 1996; 210: 85-89.

10. Min JK, An JH, Yim JH. A new technique for $\mathrm{Nd}$ : YAG laser posterior capsulotomy. Int J Ophthalmol. 2014; 7: 345-349.

11. M Zeki S. Inverted ' $U$ 'strategy for short pulsed laser posterior capsulotomy. Acta Ophthalmologica Scandinavica. 1999; 77: 575-577.

12. Levy JH, Pisacano AM. Comparison of techniques and clinical results of YAG laser capsulectomy with two Q-switched units. American Intra-Ocular Implant Society Journal. 1985; 11: 131-133.

13. MacEwen CJ, Dutton GN. Neodymium-YAG laser in the management of posterior capsular opacification--complications and current trends. Transactions of the ophthalmological societies of the United Kingdom. 1985: 105: 337-344.

14. Hawlina G, Perovšek D, Drnovšek-Olup B, Možina J, Gregorčič P. Optical coherence tomography for an in-vivo study of posterior-capsule-opacification types and their influence on the total-pulse energy required for $\mathrm{Nd}$ : YAG capsulotomy: a case series. BMC Ophthalmology. 2014; 14: 131.

15. Bhargava R, Kumar P, Phogat H, Chaudhary KP. Neodymium-yttrium aluminium garnet laser capsulotomy energy levels for posterior capsule opacification. Journal of ophthalmic \& vision research. 2015; 10: 37.

16. Khan B, Alam M, Shah MA, Bashir B, Iqbal A, Alam A. Complications of Nd: YAG Laser Capsulotomy. Pakistan Journal of Ophthalmology. 2014; 30: 134.

17. Bhargava R, Kumar P, Prakash A, Chaudhary KP. Estimation of mean ND: Yag laser capsulotomy energy levels for membranous and fibrous posterior capsular opacification. Nepal J Ophthalmol. 2012; 4: 108-113.

18. Richter CU, Arzeno G, Pappas HR, Steinert RF, Puliafito C, Epstein DL. Intraocular pressure elevation following Nd:YAG laser posterior capsulotomy. Ophthalmology. 1985; 92: 636-640.

19. Ge J, Wand M, Chiang R, Paranhos A, Shields MB. Long-term effect of $\mathrm{Nd}$ : YAG laser posterior capsulotomy on intraocular pressure. Archives of Ophthalmology. 2000; 118: 1334-1337.

20. Larrañaga-Osuna G, Garza-Cantú D. Intraocular pressure in patients undergoing capsulotomy Nd: YAG laser. Rev Med Inst Mex Seguro Soc. 2011; 49: 259-266.

21. Fourman S, Apisson J. Late-onset elevation in intraocular pressure after neodymium-YAG laser posterior capsulotomy. Arch Ophthalmol. 1991; 109: $511-513$.

22. Waseem M, Khan HA. Association of raised intraocular pressure and its correlation to the energy used with raised versus normal intraocular pressure following Nd: YAG laser posterior capsulotomy in pseudophakes. J Coll Physicians Surg Pak. 2010; 20: 524-527.

23. Terry AC, Stark WJ, Maumenee AE, Fagadau W. Neodymium-Yag Laser for Posterior Capsulotomy. American Journal of Ophthalmology. 1983; 96: 716-720.

24. Schubert HD. Vitreoretinal changes associated with rise in intraocular pressure after Nd: YAG capsulotomy. Ophthalmic Surg. 1987; 18: 19-22.

25. Stark WJ, Worthen D, Holladay JT, Murray G. Neodymium: YAG Lasers. Ophthalmology. 1985; 92: 209-212. 